\title{
Dust radiative feedback on Saharan boundary layer dynamics and dust mobilization
}

\author{
B. Heinold, ${ }^{1}$ I. Tegen, ${ }^{1}$ K. Schepanski, ${ }^{1,2}$ and O. Hellmuth ${ }^{1}$ \\ Received 11 July 2008; revised 3 September 2008; accepted 16 September 2008; published 24 October 2008.
}

[1] Mineral dust radiative effects and feedbacks upon Saharan boundary layer meteorology are estimated by means of regional dust simulations for a one-week period in May 2006. The regional dust model system LM-MUSCAT is used, which allows online interaction of the computed dust load with the solar and thermal radiation and consequently with the model dynamics. For the Bodélé depression, a mechanism is proposed that describes positive and negative dust radiative feedbacks on surface wind speeds and dust emission in dependence on atmospheric stratification, dust-induced stabilization, and baroclinity. These effects are attributed to the formation and breakdown of the low-level jet (LLJ), which is a common phenomenon in the Bodélé. However, such processes are likely also relevant for other Saharan regions. Citation: Heinold, B., I. Tegen, K. Schepanski, and O. Hellmuth (2008), Dust radiative feedback on Saharan boundary layer dynamics and dust mobilization, Geophys. Res. Lett., 35, L20817, doi:10.1029/ 2008GL035319.

\section{Introduction}

[2] Soil dust mobilized by aeolian erosion in arid and semi-arid regions represents one of the major components of atmospheric aerosol mass and changes the global and regional energy balance. It contributes to the direct aerosol effect by scattering and absorption of incoming solar radiation as well as absorption and re-emission of outgoing thermal radiation. Moreover, dust impacts the radiation budget indirectly through influences on cloud microphysics. As a consequence, it modifies atmospheric heating rates and the hydrological cycle [Miller et al., 2004; Yoshioka et al., 2007]. Dust deposition fertilizes marine and terrestrial ecosystems [Mahowald et al., 2005], which influences the $\mathrm{CO}_{2}$-cycle. The atmospheric dust distribution in turn depends on meteorological and climate conditions as well as on soil properties and vegetation cover.

[3] For accurate estimations of dust aerosol effects an adequate description of source areas and meteorological phenomena controlling dust emission is essential. However, the dust radiative impact on thermal stratification and air pressure leads to changes in surface wind speeds feeding back to the dust emission itself. Among others, Miller et al. [2004] and Pérez et al. [2006] attributed reductions in surface wind speeds and dust mobilization to changes in the planetary boundary layer (PBL) circulation that

\footnotetext{
${ }^{1}$ Leibniz Institute for Tropospheric Research, Leipzig, Germany.

${ }^{2}$ Leibniz Institute of Marine Sciences, IFM-GEOMAR, Kiel, Germany.
}

Copyright 2008 by the American Geophysical Union. 0094-8276/08/2008GL035319 result from suppressed turbulent mixing of momentum in the presence of dust. Ahn et al. [2007] explained decreased and increased surface winds by the synopticscale secondary circulation due to dust-induced pressure perturbations. While previous studies with general circulation models (GCMs) have permitted only limited insight, here the mechanisms are identified by regional-scale modeling for the largest dust source worldwide, the Saharan desert [Washington et al., 2003]. Regional model results in this study show, that the effects on surface wind speeds are related to changes in the PBL circulation and, in particular, are closely connected to the evolution of low level jets (LLJs). LLJs are pronounced, vertically limited maxima of wind speed within the PBL. They occur frequently over land worldwide [Wippermann, 1973] and were demonstrated to be important for dust mobilization in numerous Saharan regions (K. Schepanski et al., Meteorological processes forcing Saharan dust emission inferred from MSG-SEVIRI observations of sub-daily dust source activation, submitted to Journal of Geophysical Research, 2008). The low-level wind maximum results from an overshooting of the horizontal wind over the geostrophic wind in the upper PBL, which can be caused by various mechanisms. LLJs primarily form at night associated with frictional decoupling of air layers above nocturnal inversions and may persist at daytime. The wind maximum can be explained by an inertial oscillation owing to the perturbation of the geostrophic-antitriptic balance [Blackadar, 1957]. Stress divergence within the inversion may also explain the wind maximum [Wippermann, 1973].

[4] Enhanced thermal stability of PBL and/or baroclinity radiatively induced by dust may lead to an intensification of LLJs [Garrat, 1992]. The breakdown of a LLJ caused by enhanced turbulent mixing due to solar heating or wind shear can generate sufficiently high surface winds to initiate dust mobilization [Davies, 2000; Washington and Todd, 2005]. Here, a regional dust model is used to simulate Saharan dust events during the SAharan Mineral dUst ExperiMent (SAMUM) carried out in May and June 2006 in south Morocco [Heintzenberg, 2008]. On the basis of the computed dust distribution radiative forcing of Saharan dust and feedbacks on regional meteorology are analyzed. This includes proposing a mechanism, which explains dust aerosol effects on surface winds and mobilization of mineral dust in association with LLJ dynamics.

\section{Model and Methods}

[5] Dust radiative forcing and feedbacks are studied using the regional model system LM-MUSCAT [Heinold et al., 2007]. Its components are the mesoscale meteorological model Lokal-Modell (LM) from the German weather 
Table 1. Averaged Instantaneous Dust Radiative Forcing at Surface and TOA, and Net Atmospheric Radiative Forcing ${ }^{\mathrm{a}}$

\begin{tabular}{|c|c|c|c|c|c|c|}
\hline & \multicolumn{2}{|c|}{ Surface } & \multicolumn{2}{|c|}{ TOA } & \multicolumn{2}{|c|}{ Atmosphere } \\
\hline & Day & Night & Day & Night & Day & Night \\
\hline \multicolumn{7}{|l|}{ 15-21 May 2006} \\
\hline Northern Sahara & $-43(-541)$ & $+8(+94)$ & $-18(-249)$ & $+4(+26)$ & $+25(+311)$ & $-4(-84)$ \\
\hline Southern Sahara & $-50(-538)$ & $+11(+80)$ & $-19(-235)$ & $+5(+29)$ & $+31(+316)$ & $-5(-66)$ \\
\hline Bodélé region & $-87(-536)$ & $+17(+48)$ & $-32(-235)$ & $+9(+20)$ & $+55(+310)$ & $-8(-34)$ \\
\hline \multicolumn{7}{|l|}{20 May 2006} \\
\hline Northern Sahara & $-50(-419)$ & $+7(+47)$ & $-22(-195)$ & $+4(+24)$ & $+27(+255)$ & $-3(-30)$ \\
\hline Southern Sahara & $-72(-538)$ & $+15(+54)$ & $-27(-235)$ & $+7(+21)$ & $+45(+316)$ & $-8(-41)$ \\
\hline Bodélé region & $-153(-535)$ & $+24(+45)$ & $-59(-235)$ & $+14(+19)$ & $+95(+311)$ & $-10(-29)$ \\
\hline
\end{tabular}

${ }^{\mathrm{a}}$ Values in parentheses represent local maxima.

service (Deutscher Wetterdienst, DWD) and the MUltiScale Chemistry Aerosol Transport Model (MUSCAT), which includes a dust emission scheme based on Tegen et al. [2002]. Dust emission, transport, and deposition are simulated with MUSCAT on the basis of meteorological and hydrological fields from the LM. Surface properties (vegetation, surface roughness, soil texture) and the location of preferential dust sources are considered for dust flux calculations. Mobilized dust is transported as a passive tracer in five independent size classes between 0.1 and $25 \mu \mathrm{m}$ radius. The LM radiation scheme accounts for the spatio-temporal variability of modeled dust aerosol, and the dust can directly affect the meteorology and dust distribution through modifications of the radiative balance. The optical properties used to compute the changes in radiative fluxes are calculated from Mie theory using the refractive indices from laboratory measurements by Sokolik and Toon [1999]. An internal mixture of $2 \%$ hematite and $98 \%$ kaolinite is assumed with a real part of the dust refractive index of 1.52 and an imaginary part of $5.8 \times 10^{-3}$ at $550 \mathrm{~nm}$ [Helmert et al., 2007].

[6] Simulations were performed for the days 15-21 May during the 2006 SAMUM field campaign [Heinold et al., 2008]. The model domain covers an area with lower left corner on a geographical map at $\left[13.86^{\circ} \mathrm{N}, 25.35^{\circ} \mathrm{W}\right]$ and an upper right corner at $\left[47.78^{\circ} \mathrm{N}, 38.16^{\circ} \mathrm{E}\right]$ with a horizontal grid resolution of $28 \mathrm{~km}$ and 40 vertical layers. The investigation focused on dust effects in a source region, where the strongest response to dust forcing is expected. Exemplary the results for one grid point centered in the Bodélé depression $\left(17.25^{\circ} \mathrm{N}, 17.00^{\circ} \mathrm{E}\right)$ and one north-west of the Bodélé $\left(18.00^{\circ} \mathrm{N}, 16.00^{\circ} \mathrm{E}\right)$ were evaluated for 20 May 2006. The locations represent high and low concentration areas. To assess dust radiative effects, the episode was simulated twice: with radiatively active dust and without dust feedback on the LM radiation scheme. Then, the dust radiative forcing and the dynamic response were derived from differences between the results of both simulations. A cloud screening was applied to the model results to isolate the direct dust radiative effect excluding grid cells with total cloud cover $>1 \%$.

[7] The dust radiative forcing, $\Delta Q$, is the difference in net (downward " $\downarrow$ " minus upward " $\uparrow$ ") irradiances $F$ (solar plus thermal) at the tropopause due to the perturbation by mineral dust (after stratospheric readjustment, but with fixed surface and tropospheric state):

$$
\Delta Q=\left(F^{\downarrow}-F^{\uparrow}\right)_{\text {dust }}-\left(F^{\downarrow}-F^{\uparrow}\right)_{\text {clear }} .
$$

[8] However, an instantaneous change in irradiances manifests as a radiative imbalance (forcing) at the surface and the top of the atmosphere (TOA) [Intergovernmental Panel on Climate Change, 2007], hereafter referred to as surface and TOA forcing. The vertically integrated dust impact on the atmospheric radiation budget is represented by the net atmospheric forcing of mineral dust computed as TOA minus surface forcing. Together with difference plots for temperature and pressure, vertical profiles of potential temperature lapse rate, which is a criterion for thermal atmospheric stability, and wind speed from model runs including radiatively active dust and without dust forcing permit insight into the local impact of mineral dust on forcing PBL. As a measure of turbulence produced by wind shear, the gradient Richardson number $R i$ was calculated from results of the feedback and the control run indicating laminar flow $(R i>1)$, turbulent flow $(R i<0.25)$, and free convection $(R i \rightarrow-\infty)$ [Garrat, 1992].

\section{Results}

[9] The episode 15-21 May 2006 was characterized by calm weather conditions at the beginning, with a surface high centered over north-western Africa, and strong moist convective activity in the Atlas region and over Mali at the end [Knippertz et al., 2008]. As indicated by satellite observations and LM-MUSCAT simulations, dust sources were activated in, e.g., eastern and central Algeria, eastern Mauritania, Libya, Mali, and the Bodélé [Heinold et al., 2008]. For the model period, a mean dust optical thickness (DOT) of about 0.2 is computed for the northern Sahara $\left(22^{\circ}-35^{\circ} \mathrm{N}\right), 0.3$ for the southern Sahara $\left(10^{\circ}-22^{\circ} \mathrm{N}\right)$, and 0.6 for the Bodélé region. Locally, a DOT of more than 8.0 is simulated on these days. Table 1 summarizes the instantaneous surface, TOA, and net atmospheric radiative forcing of mineral dust as average over the northern and southern Sahara and the Bodélé at 12:00 and 24:00 UTC for the 20 May and 15-21 May. During noontime, there are two dust effects: the increase in albedo due to the presence of dust leading to an enhanced amount of upwelling solar radiation and the decrease of atmospheric transmission causing a reduction of incoming solar radiation at the surface. Consequently, there is a negative mean instantaneous dust forcing of up to $-87 \mathrm{~W} \mathrm{~m}^{-2}$ and $-32 \mathrm{~W} \mathrm{~m}^{-2}$ at surface and TOA, respectively. Due to absorption of incident solar radiation within the overlying dust layer the net atmospheric forcing is on average positive with up to $+55 \mathrm{~W} \mathrm{~m}^{-2}$. During midnight, the dominant dust effect is the decrease of the outgoing 

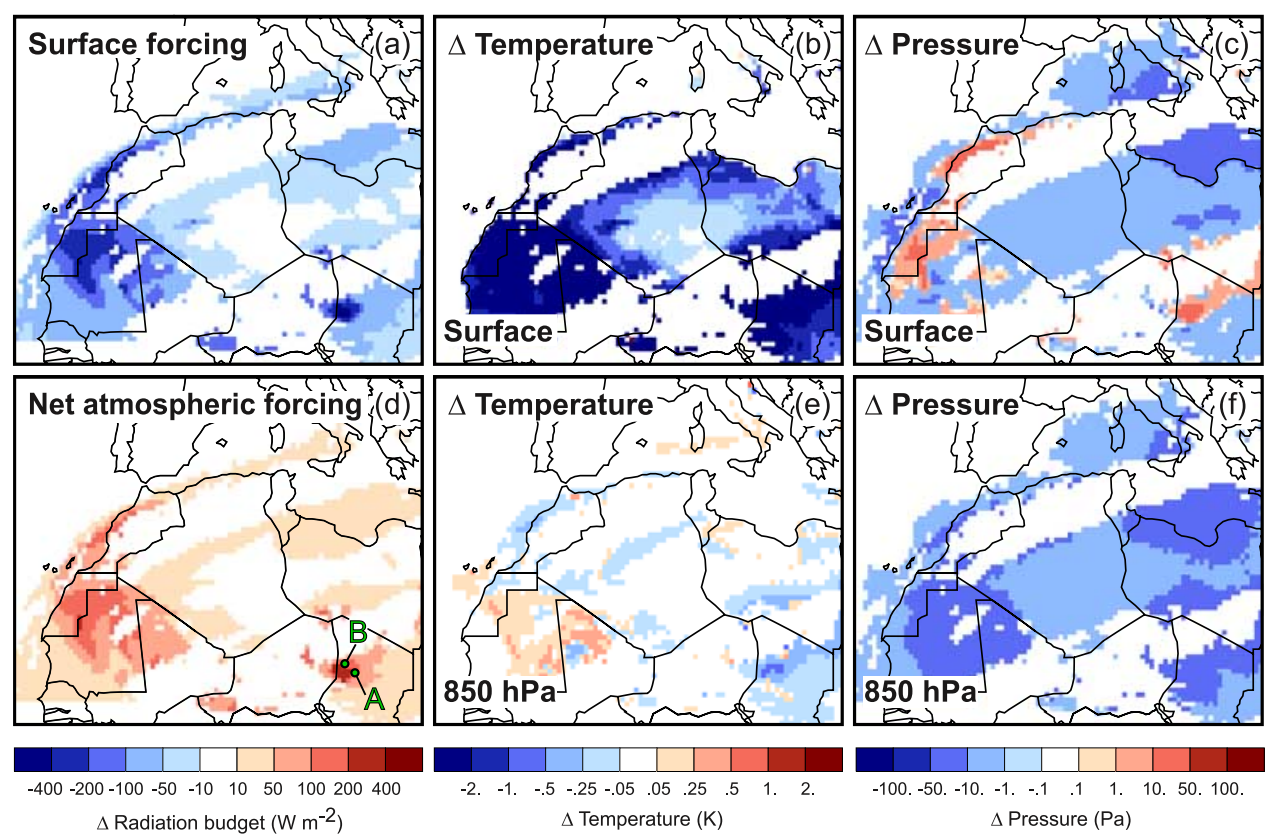

Figure 1. Dust radiative forcing at (a) surface and (d) net atmospheric forcing. Difference in the temperature and pressure between dust feedback simulation and control run at (b and c) surface and (e and f) 850-hPa level on 20 May 2006, 12:00 UTC. "A" and "B" mark the locations in Figure 3.

thermal radiation in comparison to the clear sky case. The absence of the solar effect leads to a positive dust forcing of up to $+17 \mathrm{~W} \mathrm{~m}^{-2}$ at surface and $+9 \mathrm{~W} \mathrm{~m}^{-2}$ at TOA. The averaged net atmospheric forcing of dust is negative with up to $-8 \mathrm{~W} \mathrm{~m}^{-2}$. Locally, the instantaneous surface forcing of dust reaches up to $-536 \mathrm{~W} \mathrm{~m}^{-2}$ over the Bodélé depression, which is the most active source in the Sahara. In this region, the instantaneous net atmospheric forcing of dust is positive with locally up to $+310 \mathrm{~W} \mathrm{~m}^{-2}$ at noon.

[10] As shown for 20 May, 12:00 UTC, the negative surface forcing causes an overall decrease in the surface temperature below the dust layer. Strongest reductions of locally up to $17 \mathrm{~K}$ occur in regions with highest DOT (Figure 1). On regional average, the surface temperature decrease due to dust reaches $1.3 \mathrm{~K}$ and $2.3 \mathrm{~K}$ for the northern and southern Sahara and $5.7 \mathrm{~K}$ for the Bodélé region. Since sea surface temperatures are fixed at an initial state, dust radiative effects are not computed over the sea surface. In contrast, there is a gain of radiative energy in the atmospheric column attributed to absorbed incident solar radiation within the dust layer. The effect is reflected in the $850-\mathrm{hPa}$ temperature fields with areas of increased temperature and a decrease of only $0.04 \mathrm{~K}$ on regional average in the southern Sahara. Locally, the temperature is up to $+0.6 \mathrm{~K}$ higher in the upper $\mathrm{PBL}$ (Figure 1).

[11] Thus, the main daytime effect of mineral dust is to redistribute radiative heating from the surface to the atmosphere and to stabilize the atmospheric stratification, which confirms the GCM results from Perlwitz et al. [2001] and Miller et al. [2004]. The dust radiative cooling over regions with high dust load induces sinking motion and positive pressure perturbations near the surface with an increase of up to $38 \mathrm{~Pa}$ on 20 May, 12:00 UTC. Owing to radiative heating near the dust layer top, the simulations reveal rising motion and pressure decrease there. Near the surface, the

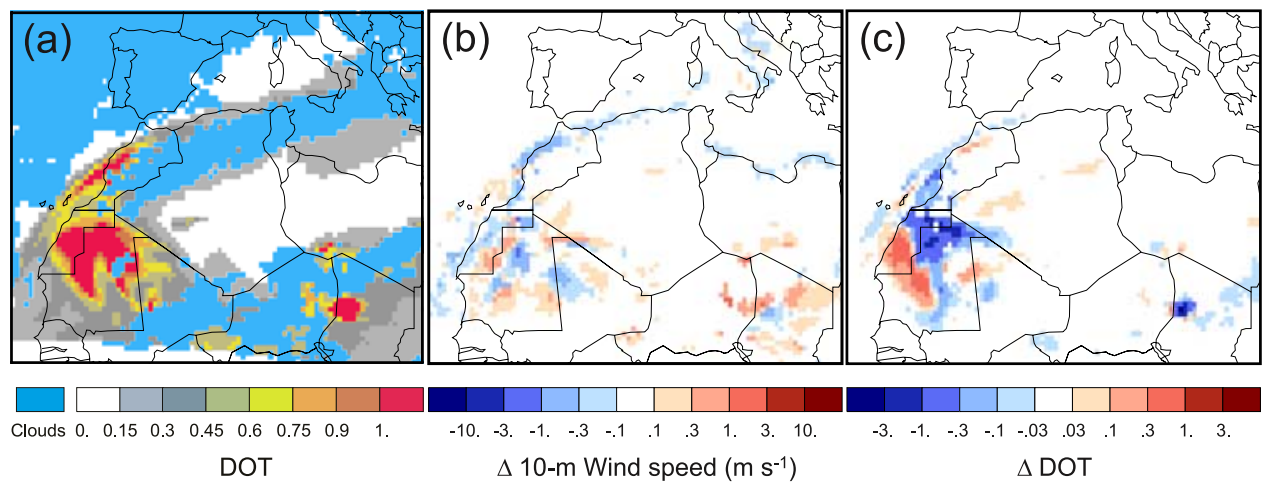

Figure 2. Maps of (a) modeled DOT (550 nm) and differences in (b) $10-\mathrm{m}$ wind speeds and (c) DOT between dust feedback simulation and control run on 20 May 2006, 12:00 UTC. 

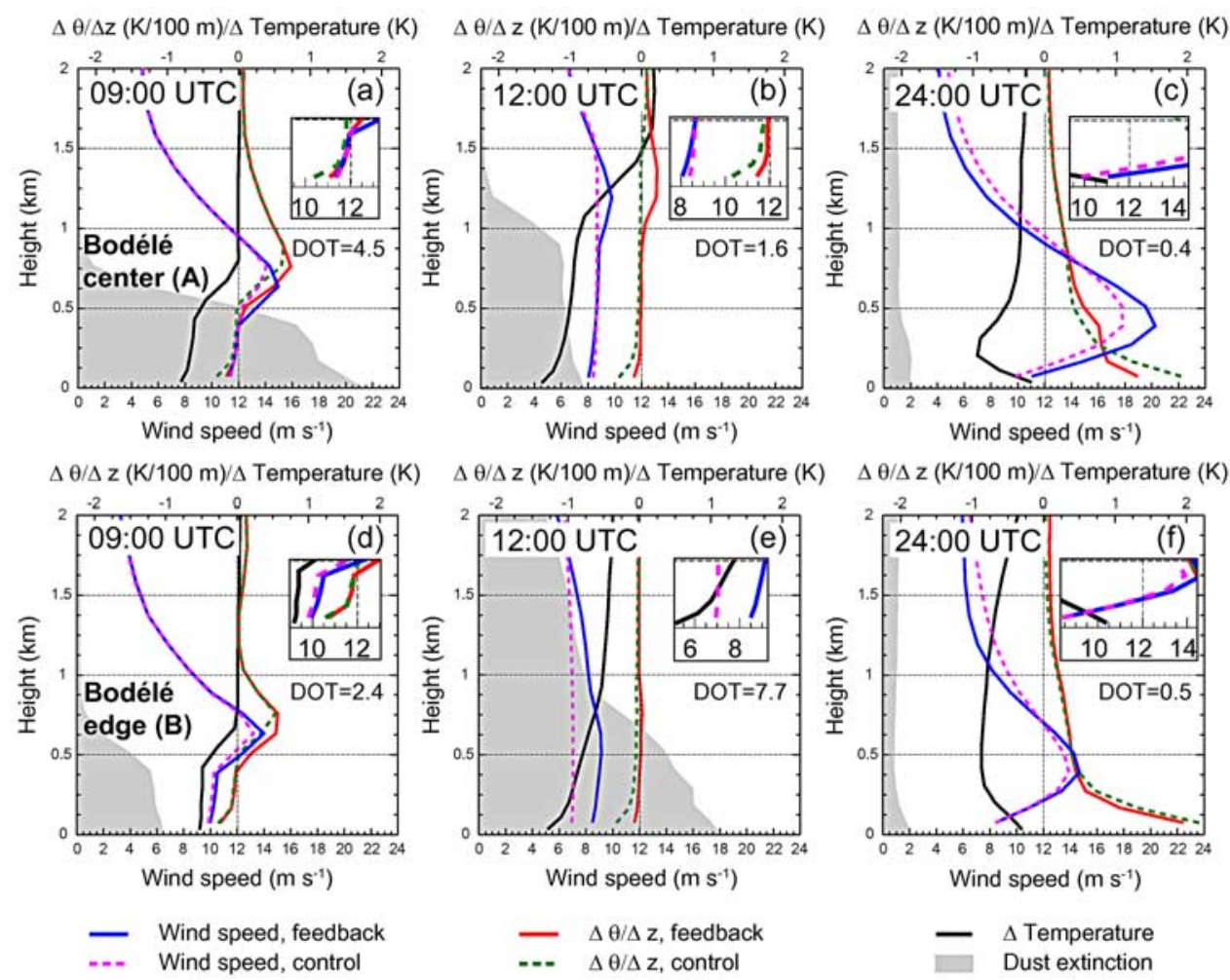

Figure 3. Vertical profiles of wind speed and lapse rate of potential temperature $\Delta \theta / \Delta z$ from the model run with and without dust radiative feedback in the $(\mathrm{a}-\mathrm{c})$ central and $(\mathrm{d}-\mathrm{f})$ north-western Bodélé. Temperature difference between both simulations and dust extinction (gray-shaded, arbitrary units). The profiles are shown for 20 May 2006.

positive pressure perturbations in high concentration areas involve negative pressure perturbations in ambient regions with low dust concentration (Figure 1). This agrees with regional modeling results by Ahn et al. [2007] for an East Asian dust event.

[12] The dynamic response to dust forcing results in both increase and decrease of surface wind speeds (Figure 2b). As described below, these impacts are closely connected with the formation and breakdown of LLJs. Figure 3 shows the diurnal PBL evolution in the center of the Bodélé and on its north-western edge on 20 May for the run with dust radiative feedback compared to the control run. In the morning hours, the two locations show nearly identical PBL features (Figures $3 \mathrm{a}$ and $3 \mathrm{~d}$ ). The model surface is intensely heated causing a superadiabatic lapse rate in the lowest $0.5 \mathrm{~km}$ in both simulations. A LLJ centers above the capping inversion at top of the mixed layer (ML). In the course of the day, the ML develops with increasing surface heating and turbulent mixing. In the control run, in the central Bodélé, the lapse rate of potential temperature and $R i<0.25$ indicate unstable conditions up to $1.5 \mathrm{~km}$ height at noon (Figure 3b). The LLJ breaks down as the turbulent mixing of heat and momentum overcomes the decoupling of near-surface air from air in the upper PBL. In the dust forcing run, the ML reaches hardly $1 \mathrm{~km}$ height $(R i<0.25)$ still with a strong capping inversion at its top. Due to the stable stratification within the upper dust layer, near-surface and upper-level air remain decoupled resulting in a preserved LLJ and about 4\% lower surface winds compared to the control run. A lower dust load is initially simulated at the Bodélé edge. The correspondingly less degree of dust-induced stabilization lead to a stronger mixing of momentum and a LLJ breakdown also in the dust feedback simulation (Figure 3e). The breakdown of the LLJ together with the more effective turbulent mixing at this location $(R i<0.25$ below $400 \mathrm{~m})$ explain the positive dust effect on surface wind speeds, which increase by up to $22 \%$ compared to the control run. As a consequence, the DOT rises to 7.7 compared to 1.6 in the central Bodélé. After sunset in the stable nocturnal boundary layer $(R i>1.5)$ a LLJ forms at the two places with stronger amplification including radiatively active dust (Figures $3 \mathrm{c}$ and $3 \mathrm{f}$ ). Since re-emission of thermal radiation by the dust layer prevents surface cooling, the thermal stratification in the lowest $250 \mathrm{~m}$ is less stable in the feedback run and momentum can be partly mixed downward. In the central Bodélé, this leads to up to $14 \%$ higher surface wind speeds than in the control run.

[13] In conclusion, mineral dust strengthens the development of LLJs at night and retards their breakdown during the day, since the stabilizing by dust and the dust-induced baroclinity support their formation and enhancement. Owinoh et al. [2005] investigated the response of the PBL flow to changes in surface heat fluxes using a theoretical model. They showed, that surface cooling of similar magnitude observed here for dust radiative cooling results in the formation of a LLJ. Depending on the initial state of atmospheric stratification and the degree of dust-induced stabilization wind speeds at surface decrease or increase.

[14] While the LLJ is a well-known phenomenon in the Bodélé depression [Washington and Todd, 2005], it also 
occurs frequently elsewhere in the Sahara, especially in mountain and West African monsoon areas (Schepanski et al., submitted manuscript, 2008). Even though other driving processes may exist, which are not explicitly analyzed here, a similar mechanism is found in Mali and Mauritania. Some indications pointed towards a seasonal cycle in the dust effects on surface winds with a more distinct negative effect during fall and winter. This might be due to lower surface temperatures and more stable conditions during these seasons. In turn, the dust radiative impact on surface wind speeds feeds back to the dust load (Figure 2c). The DOT in high concentration areas is locally reduced by $40-70 \%$, but dust production is strengthened in ambient areas of lower DOT. As the negative effect of dust on surface winds is stronger than the positive effect, the mean DOT is $3-4 \%$ lower over the cloud-free northern and southern Sahara and about 5\% lower over the Bodélé region for the investigated period. This is consistent with results from Perlwitz et al. [2001], who found in GCM experiments with more absorbing dust, that the mean dust load in the Sahara/Sahel source regions is reduced by $20-30 \%$ in winter and to a less extent in summer. In contrast, the dust concentration is up to $50 \%$ lower in summer and the reduction is smaller in winter for reflective mineral dust. For a severe dust event in the Mediterranean, Pérez et al. [2006] simulated averaged aerosol optical thicknesses lowered by $35-45 \%$ considering radiatively active dust.

\section{Summary}

[15] Dust radiative effects and feedbacks on atmospheric dynamics were investigated by Saharan dust simulations for a one-week period in May 2006 using the regional model LM-MUSCAT. In accordance with earlier studies, mineral dust was shown to modify the atmospheric stratification and to induce baroclinity. Both effects change surface winds, which are lowered or increased in dependence on the atmospheric stratification and the degree of stabilization by mineral dust. In contrast to former studies using GCMs, here the processes could be studied in detail on regional scale. For the Bodélé depression the effects were attributed to the formation and breakdown of LLJs, which benefit from dust-induced thermal stabilization and baroclinity. Higher surface wind speeds occur in dust feedback simulations compared to the control run when momentum is mixed downwards to the ground by turbulence. The surface winds decrease when thermal stratification suppresses turbulent mixing more effectively. Such processes are likely also relevant for other Saharan regions. The model results also indicate a seasonal cycle with a more dominant negative feedback on surface winds in fall and winter due to lower surface temperatures and more stable conditions. In dust feedback simulations the DOT was locally reduced by $40-70 \%$, where dust concentration is highest, but increased in surrounding areas of lower DOT. However, mean DOT is 3-4\% lower over the cloud-free Sahara and 5\% lower over the Bodélé due to the dust radiative impact. Since LLJ breakdown is an important mechanism for dust mobilization [Washington and Todd, 2005; Schepanski et al., submitted manuscript, 2008.], further observations and modeling studies are required to proof the relevance of the identified mechanism.
[16] Acknowledgments. This work is a contribution to the project SAMUM (Saharan Mineral Dust Experiment) funded by the German Research Foundation (DFG). We thank the Deutscher Wetterdienst (DWD) and the John von Neumann Institute for Computing, Jülich for good cooperation and support.

\section{References}

Ahn, H. J., S. U. Park, and L. S. Chang (2007), Effect of direct radiative forcing of Asian dust on the meteorological fields in east Asia during an Asian dust event period, J. Appl. Meteorol. Climatol., 46, 1655-1681.

Blackadar, A. K. (1957), Boundary layer wind maxima and their significance for the growth of nocturnal inversions, Bull. Am. Meteorol. Soc., $38,283-290$.

Davies, P. A. (2000), Development and mechanisms of the nocturnal jet, Meteorol. Appl., 7, 239-246.

Garrat, J. R. (1992), The Atmospheric Boundary Layer, Cambridge Univ. Press, Cambridge, U. K.

Heinold, B., J. Helmert, O. Hellmuth, R. Wolke, A. Ansmann, B. Marticorena, B. Laurent, and I. Tegen (2007), Regional modeling of Saharan dust events using LM-MUSCAT: Model description and case studies, J. Geophys. Res., 112, D11204, doi:10.1029/2006JD007443.

Heinold, B., et al. (2008), Regional Saharan dust modelling during the SAMUM 2006 campaign, Tellus, Ser. B, in press.

Heintzenberg, J. (2008), The SAMUM-1 experiment over southern Morocco: Overview and introduction, Tellus, Ser. B, in press.

Helmert, J., B. Heinold, I. Tegen, O. Hellmuth, and M. Wendisch (2007), On the direct and semidirect effects of Saharan dust over Europe: A modeling study, J. Geophys. Res., 112, D13208, doi:10.1029/ 2006JD007444

Intergovernmental Panel on Climate Change (2007), Climate Change 2007: The Physical Science Basis. Contribution of Working Group I to the Forth Assessment Report of the Intergovernmental Panel on Climate Change, edited by S. Solomon et al., Cambridge Univ. Press, New York. Knippertz, P., et al. (2008), Dust mobilization and transport in the northern Sahara during SAMUM 2006-A meteorological overview, Tellus, Ser. $B$, in press.

Mahowald, N. M., A. R. Baker, G. Bergametti, N. Brooks, R. A. Duce, T. D. Jickells, N. Kubilay, J. M. Prospero, and I. Tegen (2005), Atmospheric global dust cycle and iron inputs to the ocean, Global Biogeochem. Cycles, 19, GB4025, doi:10.1029/2004GB002402.

Miller, R. L., J. Perlwitz, and I. Tegen (2004), Feedback upon dust emission by dust radiative forcing through the planetary boundary layer, J. Geophys. Res., 109, D24209, doi:10.1029/2004JD004912.

Owinoh, A. Z., J. C. R. Hunt, A. Orr, P. Clark, R. Klein, H. J. S. Fernando, and F. T. M. Nieuwstadt (2005), Effects of changing surface heat flux on atmospheric boundary-layer flow over flat terrain, Boundary Layer Meteorol., 116, 331-361.

Pérez, C., S. Nickovic, G. Pejanovic, J. M. Baldasano, and E. Özsoy (2006), Interactive dust-radiation modeling: A step to improve weather forecasts, J. Geophys. Res., 111, D16206, doi:10.1029/2005JD006717.

Perlwitz, J., I. Tegen, and R. L. Miller (2001), Interactive soil dust aerosol model in the GISS GCM: 1 . Sensitivity of the soil dust cycle to radiative properties of soil dust aerosols, J. Geophys. Res., 106, 18,167-18,192.

Sokolik, I. N., and O. B. Toon (1999), Incorporation of mineralogical composition into models of the radiative properties of mineral aerosol from UV to IR wavelengths, J. Geophys. Res., 104, 9423-9444.

Tegen, I., S. P. Harrison, K. Kohfeld, I. C. Prentice, M. Coe, and M. Heimann (2002), Impact of vegetation and preferential source areas on global dust aerosol: Results from a model study, J. Geophys. Res., 107(D21), 4576, doi:10.1029/2001JD000963.

Washington, R., and M. C. Todd (2005), Atmospheric controls on mineral dust emission from the Bodélé Depression, Chad: The role of the low level jet, Geophys. Res. Lett., 32, L17701, doi:10.1029/2005GL023597. Washington, R., M. Todd, N. J. Middleton, and A. S. Goudie (2003), Duststorm source areas determined by the Total Ozone Monitoring Spectrometer and surface observations, Ann. Assoc. Am. Geogr., 93(2), 297-313. Wippermann, F. (1973), Numerical study on the effects controlling the lowlevel jet, Beitr. Phys. Atmos., 46, 137-153.

Yoshioka, M., N. Mahowald, A. J. Conley, W. D. Collins, D. W. Fillmore, C. S. Zender, and D. B. Coleman (2007), Impact of desert dust radiative forcing on Sahel precipitation: Relative importance of dust compared to sea surface temperature variations, vegetation changes, and greenhouse gas warming, J. Clim., 20(8), 1445-1467.

B. Heinold, O. Hellmuth, K. Schepanski, and I. Tegen, Leibniz Institute for Tropospheric Research, Permoser Straße 15, D-04318 Leipzig, Germany. (heinold@tropos.de) 